\title{
DENTRO OU FORA DA TEORIA?
}

\section{IN OR OUT OF THEORY?}

\author{
Renata Coelho MARCHEZAN \\ UNESP-Universidade Estadual Paulista
}

\begin{abstract}
RESUMO: Há etapas da vida de uma teoria em que ficam mais evidenciadas, mais frequentes e mais intensas as suas transformações. São etapas também de incertezas e polêmicas, e, por isso mesmo, produtivas e estimulantes. É nesse contexto de dinamicidade que este artigo situa a teoria semiótica greimasiana, para, com base na obra Da imperfeição do mesmo Greimas, identificar e refletir sobre proposições e métodos cujo estatuto teórico na semiótica não é consensual.
\end{abstract}

PALAVRAS-CHAVE: Semiótica; Apreensão Estética; Leitura; Paradigma Indiciário; Discurso em Ato.

\begin{abstract}
There are stages in a theory's life, in which its transformations are more frequent, more intense and in a position of more evidence. They are also stages of uncertainty and controversies, and, therefore, productive and stimulant. It is in this context of dynamism that this article situates the Greimasian semiotics theory, in order to, based in the work Da imperfeição by the same Greimas, identify and reflect about propositions and methods, whose theoretical statute in the semiotics is not general consent.
\end{abstract}

KEYWORDS: Semiotics; Aesthetics Aprehension; Reading; Indiciary Paradigm; Discourse in Act.

Dentro ou fora da teoria? Sem buscar, principalmente, escolher uma das alternativas, antes, para tentar propor uma reflexão, trazemos, neste texto, noções, proposições cujo estatuto teórico não é afirmado consensualmente na semiótica. São elas coletadas no livro: Da imperfeição, de A. J. Greimas (2002) ${ }^{1}$, obra publicada originalmente em 1987, ainda hoje, considerada de dentro e de fora da semiótica. Nessa edição brasileira - e para ficar apenas nela -, que inclui textos de apresentação, inclusive de outras edições, R. Dorra qualifica o livro como "perturbador" (2002, p. 123), "uma empresa poética" (2002, p. 122), E. Landowski o considera "fonte de inspiração" (2002, p. 125), P. Fabri o toma como "parábolas" (2002, p. 109) e A. C. Oliveira afirma sua contribuição decisiva para a "revitalização da semiótica" (2002, p. 9).

As expressões 'estar dentro e fora', 'circular entre fronteiras', embora, aqui, as tenhamos retirado de T. Eagleton (2005), podem até ser arroladas como palavras de ordem de nossa época. Talvez por isso, ou apesar disso, fique difícil resistir a elas.

\footnotetext{
${ }^{1}$ Trata-se da edição brasileira.
} 
Com outras palavras: Da imperfeição traz o Greimas de 'dentro', antecipadamente esperado por seus assíduos leitores, mas traz, juntamente com este, um outro Greimas surpreendente (de 'fora'?), que, após mais de vinte anos da publicação da obra, ainda causa admiração, e motiva discussões. Um semioticista imperfeito, na acepção da obra examinada, que, mais supreende, porque se trata de Greimas. É exatamente essa imperfeição, que, aqui, tentamos considerar. Não tanto, confessamos, para desestabilizar, com o imprevisto, o nosso cotidiano de certezas teóricas, que, nestes anos, não temos mais. Mas porque assim é preciso - para tentar debater e qualificar as imperfeições. Passada a surpresa, para alguns, o susto, para outros, o que nos desvela essa saborosa e densa obra imperfeita?

O fecho final de um livro, nem sempre, traz sua principal conclusão, mas se for para começar por ela, afirmaríamos que Da imperfeição mostra o homem em busca do sentido da vida, que vai encontrar apenas pequenos e vários sentidos, efêmeros, simples, um quase nada que é, no entanto, tudo.

Lição de vida? Lição teórica? É esta última pergunta que move nossa reflexão. Não que outros não tenham se ocupado da questão - as mencionadas apresentações da edição da obra, elas mesmas nos desmentiriam logo -, mas, apesar disso, buscamos coletar um conjunto pertinente, de argumentações, de lições, que buscamos sustentar com citações ${ }^{2}$.

\section{PRIMEIRA LIÇÃO}

Sem prejuízo da conclusão, mais filosófica, que indicamos acima, devemos destacar que o objetivo, mais semiótico, de Da imperfeição, é contribuir para a identificação e para a descrição da apreensão estética. Uma primeira lição, mesmo que não seja nova, merece ser destacada: o objetivo da obra tem foco particular, não é posicionado para abarcar o todo, para descrever exaustivamente a constituição do sentido, na sua totalidade.

\section{SEGUNDA LIÇÃO}

No exame da apreensão estética, que a obra propõe, a materialidade examinada, como é tradicional na semiótica, é o texto. Mais exatamente, trecho de texto: uma segunda lição, relacionada à primeira. O recorte de uma totalidade, realizado pelo pesquisador, em função de seus objetivos de análise: "Somente a descrição da apreensão estética nos interessa" (GREIMAS, 2002, p. 32) ${ }^{3}$.

E, até, não somente trecho de texto, mas também relato de trecho de texto: "O relato do feliz evento que acabamos de resumir permite reconhecer as principais articulações da sequiência discursiva que supostamente relata uma apreensão estética excepcional" (GREIMAS, 2002, p. 25) ${ }^{4}$.

O "feliz evento" é de Michel Tournier; os demais trechos recortados e analisados, também de obras literárias, são de Ítalo Calvino, Rainer Maria Rilke, Tanizaki Junichiro e Julio Cortazár. Todos eles escolhidos, porque, para Greimas, expõem uma apreensão estética, de diferentes modos e com base em concepções diferentes de estética.

\footnotetext{
${ }^{2}$ A primeira parte de Da imperfeição é dedicada à análise de textos literários. Ao citarmos, neste artigo,essas análises, indicaremos, em nota, a obra literária e o autor a que se referem.

${ }^{3}$ Da análise de Palomar, de Ítalo Calvino.

${ }^{4}$ Da análise de Sexta-feira, ou Os limbos do Pacífico, de Michel Tournier.
} 
Com o segundo autor analisado, Greimas reforça o que identificamos como primeira e segunda lições:

[...] [a] volta à origens de todas as coisas tem por corolário uma atitude analítica que repousa sobre um fundo epistemológico que conduz a uma estética da decomposição. Cada corpúsculo é independente, cada partícula da matéria contém em potência todas as formas e energias que se constituem na superfície. Todo objeto é digno de consideração: uma folha que cai, como diz Calvino em uma passagem japonizante de Se um viajante numa noite de inverno, é um mundo em si. A obsessiva intenção de totalidade que praticamos pode ser substituída pela contemplação do infinitamente pequeno: totus ou unus, isso resulta no mesmo (GREIMAS, 2002, p. 52) ${ }^{5}$.

Mais do que a opção exclusiva pelo fragmento - o que não é definitivamente o caso - as lições acima podem regular nossa "ambição totalizante" (GREIMAS, 2002, p. 89), podem multiplicar os modos de ver, tornando-os mais próximos dos objetos.

Nas análises dos trechos dos textos, em que se reconhecem, em operação, conhecidos conceitos da semiótica, identifica-se uma fratura da rotina, uma ruptura com o cotidiano, uma imperfeição no parecer, que, mesmo brevemente, sugere um outro sentido, uma outra ordem, uma outra dimensão, fora do ritual do dia-a-dia. Mesmo sendo mais figurativos, e não o são por acaso, os termos - fratura, ruptura, imperfeição - deixam claro a isotopia da diferença, da descontinuidade, que permite a oposição de pares diferenciados. $\mathrm{Na}$ descrição da apreensão estética, além da descontinuidade, também está em operação a não solução de continuidade, em que se resgata a continuidade entre os conceitos sujeito e objeto: a visão ${ }^{6}$ do objeto, que, na apreensão estética, no entanto, também se move, se altera, se rompe, atinge o sujeito que o vê, e o controla. $\mathrm{O}$ objeto imobiliza o sujeito. O objeto age, torna-se também sujeito. Invertem-se os papéis, ou, antes, mesmo que por um breve momento, os papéis que os definem mostram-se misturados, imprecisos. Há temporariamente uma suspensão das distinções.

A apreensão estética é essa "relação particular estabelecida, no quadro actancial, entre um sujeito e um objeto" (GREIMAS, 2002) ${ }^{7}$, imperfeição que transfigura a tela do parecer a que estamos habituados.

\section{TERCEIRA LIÇÃO}

Da imperfeição reafirma a convicção da importância do texto, de tal maneira que é ele também, a lógica do texto, não somente um modelo teórico, uma lógica teórica, que orienta a análise. Uma terceira lição pode ser assimilada quando buscamos flagrar o início da análise, a entrada do analista no texto. Nas citações das páginas 25 e 32, já introduzidas acima, podemos acompanhar o semioticista a delimitar um trecho-objeto. Feito isso, põe-se a examinar o deslumbramento, que o texto literário descreve e que, em seguida, ele próprio retoma nostalgicamente. Com as outras citações, abaixo, podemos continuar a seguir o método do analista em sua abordagem do texto:

\footnotetext{
${ }_{6}^{5}$ Da análise de Elogio da sombra, de Tanizaki Junichiro.

${ }^{6}$ Lembra Greimas [...] que "visão", já mesmo em definição de dicionário, opõe-se à realidade.

${ }^{7}$ Não é propósito deste texto explorar essa questão, tão bem explorada na própria obra Da Imperfeição. Como também, para citar apenas outra, em Oliveira; Landowski (1995).
} 
Este curto poema, que se presta a todas as análises, abre um amplo leque de parâmentros de exploração. O primeiro que vem ao espírito é o dispositivo dos tempos verbais, que opõe o presente do primeiro verso ao passado que se estende pelo resto do texto (GREIMAS, 2002, p. 41) ${ }^{8}$

Esta breve passagem "estética" se encontra, como se vê, duplamente enquadrada: como uma imobilização momentânea do sujeito entre dois deslocamentos ordinários [...] (GREIMAS, 2002, p. 33) .

O texto, aparentemente muito simples, decompõe-se com facilidade em duas sequências que são separadas por uma interpelação ao leitor [...] (GREIMAS, 2002, p. 49) ${ }^{10}$.

[...] a frase-pivô do texto [do texto literário analisado]:

'Um diálogo envolvente corria pelas páginas como um riacho de serpentes [...]' (GREIMAS, 2002, p. 61) ${ }^{11}$.

Diante de várias opções, de caminhos a seguir, o semioticista escolhe aquele que primeiro lhe "vem ao espírito" (citação da página 41); detém-se na "imobilização momentânea do sujeito", que lhe capta a atenção (citação da página 33); elege a separação de duas seqüências que reconhece com facilidade (citação da página 49); destaca uma frase que considera "pivô" (citação da página 61). Sobre a primeira citação, ainda é interessante pontuar, para enfatizar a ação do analista, que a oposição entre os tempos verbais, que, primeiramente, lhe chama a atenção e impulsiona a análise, não foi preservada por outra leitura, a do tradutor brasileiro. Quem faz essas escolhas - não estamos esquecidos disso - é alguém qualificado teoricamente, mas que não aplica um modelo de modo impessoal, um modelo sem causa. Enfatizamos, aqui, a lição do método, que expressa a relação que a teoria, em sua aplicação, tem com o objeto.

\section{QUARTA LIÇÃO}

O método expõe o procedimento do analista, que, se não antes de tudo, é sempre um leitor. As citações acima sugerem também isso, e o faz, mais ainda, a grande recorrência, na obra, das figuras da leitura, do leitor. Indicamos outros segmentos que também sustentam essa quarta lição:

Com estas sentimentalidades, um pouco murchas, o leitor é finalmente convocado a uma meditação sobre a fragilidade do ser e, se ele for capaz, a uma apreensão estética da evanescência (GREIMAS, 2002, p. 45).

Um perigo incessante ronda a nossa descrição, um risco presente a cada instante, de confundir - ou ao menos inverter - os três planos de

\footnotetext{
${ }^{8}$ Da análise de poema de Rainer Maria Rilke.

${ }^{9}$ Da análise de Palomar, de Ítalo Calvino.

${ }^{10} \mathrm{Da}$ análise de Elogio da sombra, de Tanizaki Junichiro.

${ }^{11}$ Da análise de Elogio da sombra, de Tanizaki Junichiro.
} 
leitura desse texto: a encenação da apreensão estética [...] o devaneio do poeta [...] e, enfim, o poema ele mesmo, objeto estético por excelência, que, como tal, se oferece a nós, os leitores. (GREIMAS, 2002, p. 45) ${ }^{12}$.

A possível confusão é solucionada pela distinção de níveis, objetivamente, postulados pela semiótica. Ao lado disso, tomemos da citação a reiteração da figura da leitura, a identificação do analista com o leitor, com os leitores, que têm o poema como objeto estético. O que queremos é situar o vigor, a vocação atual da semiótica como uma teoria da leitura.

A própria experiência estética pode ocorrer em um ato de leitura, em que, conforme já pontuamos, o sujeito-leitor é surpreendido por seu objeto de leitura. Para Greimas, a leitura socializada dá lugar a uma imperfeição, a uma outra leitura fora dos padrões do cotidiano:

Tudo ocorre como se, no encontro das gestalten - formas sob as quais as figuras do mundo se erguem diante de nós -, nossa leitura socializada se projetasse à frente e as vestisse, transformando-as em imagens, interpretando as atitudes e os gestos, inscrevendo as paixões nos rostos, conferindo graça aos movimentos. Porém também é como se, às vezes, em vista de uma 'deformação coerente' do sensível - como diria Merleau-Ponty -, uma leitura segunda, reveladora das formas plásticas, fosse à frente das formas iconizáveis e reconhecesse nelas correspondências cromáticas e eidéticas 'normalmente' invisíveis e outros formantes mais ou menos 'desfigurados' aos quais ela se apressaria a atribuir novas significações (GREIMAS, 2002, p. 73-74)

Greimas insiste no uso do termo leitura e a conceituação que lhe atribui diz respeito também a objetos não-verbais, como é de se esperar na semiótica. O exemplo que recolhe é o da mulher que olha vitrinas. Para o autor, essa mulher, além de perceber o conjunto de figuras que visualmente compõe um vestido, como "linhas, cores, gestos, atitudes", também aplica a ele uma outra "grade de leitura", e reconhece-lhe "simplicidade, elegância, refinamento" (77).

O termo leitura é bem produtivo: o autor reconhece tipos de leitura - "leitura socializada" e "leitura segunda" -, aplicados a diferentes objetos - verbais e não-verbais - e localizados em vários planos - a leitura do semioticista, enunciador de Da Imperfeição, a leitura do enunciador do texto literário que analisa e a leitura do ator, ou, em outras palavras, do personagem do texto literário em pauta.

Ao realçar, com Greimas, a importância da leitura, não estamos nos esquecendo de que os níveis de profundidade do percurso gerativo de sentido, da teoria semiótica, não constituem um modelo hipotético que descreveria a competência do sujeito produtor e receptor de texto, ou seja, não correspondem a um conjunto de processos mentais empregados pelo sujeito que produz e interpreta um texto. O que entendemos poder aprender, com Da imperfeição, é uma lição de método: o destaque dado ao sujeito que lê, ao sujeito que analisa, ao sujeito diante do seu objeto; o sujeito que, em sua atividade de leitura, nessa acepção bem estendida, põe em funcionamento suas grades de leitura, entre as quais se incluem os filtros teóricos.

\footnotetext{
${ }^{12}$ Da análise de poema de Rainer Maria Rilke.
} 


\section{QUINTA LIÇÃO}

Na descrição da apreensão estética, consideram-se, igualmente, conforme já pontuamos e em relativa continuidade, sujeito e objeto. Na citação a seguir, a análise da "Continuidade dos parques", de Cortazár, indica uma caracterização do sujeito da apreensão estética: é um sujeito 'absorvente'. A leitura da leitura. O conto narra a absorção, a imersão do leitor na história lida, que se torna real, para ele próprio.

Nosso propósito não é submeter a uma análise rigorosa esse belo texto, mas nos servir dele para tentar compreender, além do modo de ser de um objeto literário, sua relação sutil com o sujeito 'absorvente' (GREIMAS, 2002, p. $60)^{13}$.

À obra Da imperfeição, que abdica de "uma análise rigorosa", interessa a "relação sutil [do objeto estético] com o sujeito 'absorvente". A nós também, para mostrar a "relação sutil" que envolve o próprio semioticista, em todos os passos da análise. Uma quinta lição. É também 'absorvente', 'absorvedor', o analista, que se move, se comove, ora se aproxima, ora se afasta do objeto. Sujeito do saber ${ }^{14}$ e do sentir, presente também na própria escrita.

Às voltas com a descrição do sensível, a análise e o semioticista, eles também, se sensibilizam. Em relativa continuidade, o que resta ao protagonista de "Continuidade dos parques" parece ser também o que resta ao enunciador de Da imperfeição: "Uma efêmera sensação tátil, o contato delicado do sujeito com o outro - o veludo, a face [...] - é tudo o que resta quando não há nada mais a esperar" (GREIMAS, 2002, p. 65) ${ }^{15}$.

O sujeito-autor de Da imperfeição, instalado na obra, é um sujeito racional, o esperado semiocitista, mas é também o inesperado, um sujeito 'absorvente', 'absorvedor' dos objetos literários que analisa. $\mathrm{O}$ abalo do sujeito diante do objeto de análise. $\mathrm{O}$ analista pode até confessar dúvidas, como a do final da análise do texto de Tanizaki Junichiro: "Recusa inconsciente, reflexo de ato-defesa diante do insustentável. Horror ao sagrado?" (GREIMAS, 2002 , p. 53) ${ }^{16}$.

Não é apenas com as citações acima que podemos defender a relativa continuidade entre a teoria e a vida. A relação é recorrente, como a reclamar ao analista a sutileza, a sensibilidade, a absorção no seu próprio corpo da sensibilidade do outro. A reflexão sobre a relação entre vida, arte e teoria continua:

[...] em que medida estas apreensões 'de papel', elas mesmas já estetizadas, refletem as experiências estéticas que vivem os sujeitos históricos 'reais'? E, admitindo que se trate de simulacros dignos de fé e utilizáveis eventualmente como modelos discursivos que permitam analisar os comportamentos humanos 'vividos', são elas somente configurações parciais emergentes de uma episteme localizável, a do século $\mathrm{XX}$, ou bem nos dizem algo de nossa condição humana? São questões de método que a semiótica se põe sem cessar e que ela vive com lucidez (GREIMAS, 2002, p. 69-70).

\footnotetext{
${ }^{13}$ Da análise de "Continuidade dos parques", de Julio Cortazar.

${ }^{14}$ Na p. 71, recorda-se com Greimas (2002): "o latim sapere, ter sabor, converte-se em saber".

${ }^{15}$ Da análise de "Continuidade dos parques", de Julio Cortazar.

${ }^{16}$ Da análise de Elogio da sombra, de Tanizaki Junichiro.
} 
Nesta argumentação, interessa apontar a insistência na repetição das figuras relacionadas à vida. Da citação acima, depreendem-se: "vivem", "vividos", e mesmo "sujeitos históricos 'reais", "experiências". Na mesma página 69, aparecem: "fatia de vida", "penetra na vida".

A abstração teórica é relativizada, adquire vida, é preenchida por experiências vividas. O objeto focado não é dessorado de vida, não é desterrado, não é perpetuado: “[...] a vestimenta não adquire sentido a não ser quando ela 'veste' a mulher" (GREIMAS, 2002, p. 84). Nas palavras da apresentação de E. Landowski (2002, p. 126): “[...] não há ruptura entre o nível "científico" da conceitualização e o plano da experiência vivida". No entanto, enfatizemos: não se trata também de fusão, de homogeneização entre o científico e o vivido, mas, sim, do estabelecimento de relações entre eles. Desse modo, explica-se também a escolha não casual, conforme já apontamos, por termos teóricos menos abstratos, cujo caráter figurativo revela a experiência sensível do mundo.

$\mathrm{O}$ analista não é alheio do objeto que analisa e não se posta distanciado dele. A teoria não é um escudo para proteger o objeto das disposições do sujeito. Deve, sim, servir ao analista e ao objeto. Essa é uma boa lição, não tanto para os necessários estudos teóricos, mas para os trabalhos de análise que têm hipertrofiado a teoria e rebaixado o texto à categoria de exemplo, de ilustração.

\section{SEXTA LIÇÃO}

Já é o momento de revelar, aqui, a pergunta que fizemos ao longo da nossa primeira leitura de Da imperfeição: as lições recolhidas restringem-se à experiência estética, ao tratamento do objeto estético? A resposta, que, neste texto, enumeramos sexta lição, vem no último capítulo. As inquietações, a reflexão sobre a apreensão estética, as respostas obtidas, ao longo do livro migram, no fecho da obra, para o cotidiano, para o aqui-agora, pobre de valores, insignificante, rotineiro, sem esperas, sem esperanças. Se o dia-a-dia reclama a atenção, seu tratamento também é estetizante: postula-se

[...] a possibilidade de ressemantização dos objetos gastos que nos rodeiam e das relações intersubjetivas esgotadas ou prestes a ser [...] Existiriam modos de dar mais densidade à vida, de entrecortá-la de eventos "estéticos" a partir de desvios do funcional [...]. Entre as práticas do gosto socializado, que conduzem à usura das categorias estéticas e o grande evento, que talvez acontecerá, existirá um caminho pessoal por traçar, um caminho para a esperança? (GREIMAS, 2002, p. 85-86).

A proposta acentua o papel do sujeito, sua ação, sua competência para encontrar a imanência do sensível, na imperfeição, entre a nostalgia e a esperança, e por causa delas. A ressemantização constitui um modo de olhar a vida, a "nossa pobre vida cotidiana" (GREIMAS, 2002). O autor sabe, no entanto, das limitações de seu "projeto de vida", que, como suspeita, pode ser considerado "ingênuo", "arcaico", "excessivamente estético/estetizante", mas, a essa altura, já ficou claro: suas interrogações não buscam resposta decisiva, geral, universal; contentam-se, antes, com as possibilidades, com os fragmentos, com o efêmero. 
CASA, Vol.7 n.2, dezembro de 2009

Pode-se sonhar: e se, no lugar de uma ambição totalizante que procura transfigurar toda a vida e põe em jogo o conjunto do percurso do sujeito, este pudesse proceder a um desmembramento de seus programas, à valorização do detalhe do vivido? Se um olhar metonímico e demorado se dedicasse a abordar com seriedade as coisas simples?... (GREIMAS, 2002, p. 89).

\section{Referências Bibliográficas}

BERTRAND, Denis. Caminhos de semiótica literária. Bauru, SP: EDUSC, 2001.

DORRA, Raúl. Perspectiva da semiótica. In: GREIMAS, Algirdas Julien. Da imperfeição. São Paulo: Hacker Editores, 2002. Trad.: Ana Cláudia Oliveira.

EAGLETON, Terry. Depois da teoria. Um olhar sobre os Estudos Culturais e o pósmodernismo. Rio de Janeiro: Civilização brasileira, 2005.

FABBRI, Paolo. Introdução. In: GREIMAS, Algirdas Julien. Da imperfeição. São Paulo: Hacker Editores, 2002. Trad.: Ana Cláudia Oliveira.

GINZBURG, Carlo. Mitos, emblemas, sinais: morfologia e história. São Paulo: Companhia das letras, 1990.

GREIMAS, Algirdas Julien. Da imperfeição. São Paulo: Hacker Editores, 2002. Trad.: Ana Cláudia Oliveira.

LANDOWSKI, Eric. De l'imperfection, o livro do qual se fala. In: GREIMAS, Algirdas Julien. Da imperfeição. São Paulo: Hacker Editores, 2002. Trad.: Ana Cláudia Oliveira. OLIVEIRA, Ana Cláudia de. Prefácio. In: GREIMAS, Algirdas Julien. Da imperfeição. São Paulo: Hacker Editores, 2002. Trad.: Ana Cláudia Oliveira.

OLIVEIRA, Ana Cláudia de; LANDOWSKI, Eric. (eds.). Do inteligível ao sensível. São Paulo: Educ, 1995. 